\title{
AÇÃO DOCENTE EM CIÊNCIAS NATURAIS NA EDUCAÇÃO DE JOVENS E ADULTOS: TÉCNICA OU REFLEXÃO CRÍTICA?
}

\author{
Lucas Vilas Boas Simirio \\ Universidade do Oeste Paulista - UNOESTE, Mestrado em Educação, Presidente Prudente, SP. E-mail: \\ luketv1@hotmail.com
}

\section{RESUMO}

O presente trabalho, busca compreender, a partir de uma discussão histórico-crítica, quais proposições teórico-metodológicas (professor como técnico ou crítico-reflexivo) se revelam nas práticas educativas de docentes em Ciências Naturais na Educação de Jovens e Adultos (EJA) no Brasil. Portanto, se valeu de uma revisão de literatura problematizada sobre a temática, com base em bibliografias específicas e busca em base de dados como BDTD, Scielo e periódicos da Capes, cujos descritores foram: EJA, ensino de Ciências, pedagogia histórico-crítica, professor técnico e professor crítico-reflexivo. Assim, concluiu-se que a ação docente em Ciências Naturais na EJA ainda precisa superar sua condição de pura racionalidade técnica no tocante a suas bases teóricometodológico-epistemológicas, pois ainda é bastante tecnicista, com vista assim, à obtenção de um ensino mais sócio-histórico, de cunho reflexivo e respaldo crítico.

Palavras-chave: Ensino de Ciências Naturais. Educação de Jovens e Adultos (EJA). Pedagogia histórico-crítica. Reflexão-crítica. Tecnicismo.

\section{TEACHING ACTION IN NATURAL SCIENCES IN YOUTH AND ADULT EDUCATION: TECHNIQUE OR CRITICAL REFLECTION?}

\begin{abstract}
The present work seeks to understand from a historical-critical discussion, which theoreticalmethodological propositions (teacher as technician or critic-reflexive) are revealed in the educational practices of teachers in Natural Sciences in Youuth and Adults Education (EJA) in Brazil. Therefore, it was used a review of problematized literature on the subject based on specific bibliographies and search databases such as BDTD, Scielo and Capes journals, whose descriptors were: EJA, science teaching, historical-critical pedagogy, technical professor and critical-reflective teacher. Thus, it was concluded that the teaching action in Natural Sciences in the EJA still needs to overcome its condition of pure technical rationality in relation to its theoretical-methodologicalepistemological bases, since it is still quite technical, with a view to obtaining a more sociohistorical, reflexive and critical support.

Keywords: Teaching of Natural Sciences. Youth and Adult Education (EJA). Historical-critical pedagogy. Reflection-criticism. Technicality.
\end{abstract}




\section{INTRODUÇÃO}

Frente um paradigma histórico-crítico, ensinar pressupõe compreensão da prática social, o que de sobremaneira vincula a atividade docente às questões humanas, à contradição, à problematização e principalmente à mediação elucida Saviani (1997). Também, o processo de ensino dentro desta abordagem contesta uma ação docente em geral, mas em particular das Ciências Naturais, reduzida e caracterizada pela simples transmissão de métodos e técnicas, bem como, conteúdos teóricos descontextualizados. (BRASIL, 1998; CACHAPUZ, et al., 2005).

Diante desse panorama, um ensino de Ciências, sobretudo na Educação de Jovens e Adultos (EJA), precisa se histórico e culturalmente orientado, isso porque os discentes desta modalidade carecem de oportunidades educativas ajustadas às significações cotidianas e laborais, tão logo, a ação docente ali implementada requer adoção de práticas de cunho reflexivo e crítico e seja de relevância sociocultural no contexto que se desenvolve. (AUGUSTINHO, 2010; BRASIL, 2016; CONTRERAS, 2002; FREIRE,1996; SAVIANI, 1997).

Deste modo, a ação docente na EJA, precisa aproximar-se ao debate, a compreensão e sistematização das questões tecnológicas e científicas, do antagonismo político e das injustiças determinadas pelo capital, como forma de propiciar a formação integral e humana dos sujeitos aprendentes para a formação de uma sociedade democrática, enfatizam Contreras (2002) e Saviani (1997).

Ocorre pois que, os professores desta modalidade não estão sendo formados e nem recebendo o preparo para uma atuação profissional que comtemple o novo panorama social do ensino. Por isso, assistimos um profícuo despreparo científico e pedagógico de docentes de Ciências no contexto atual, o que os impelem em grande parte, de práticas inovadoras, criativas, reflexivas e críticas. (AUGUSTINHO, 2010; FREIRE, 1996; LEITE e DI GIORGI, 2004).

Sobre este panorama, Contreras (2002) e Schõn (1983) afirmam que, o conhecimento em Ciências físico-naturais é em geral visto como empírico-analítico, ou seja, a ideia do conhecimento científico explicada pela base filosófica e epistemológica do positivismo, que estrutura o modelo chamado de racionalidade técnica, o qual, concebe o professor como profissional técnico.

Em decorrência disso, observa-se que a racionalidade técnica, segundo expressam Contreras (2002) e Schõn (1983), se apresenta como uma vinculação do ensino ao ideário profissional, ou seja, uma aproximação da educação em geral e do ensino em particular, ao viés produtivista e mercadológico puramente instrumental, técnico, especializado, a partir a partir de um conhecimento teórico prévio do qual professor e aluno não participam da sua elaboração nem aplicação.

Como efeito, observa-se que em termos teóricos e metodológicos, a disciplina de Ciências na EJA, foi e ainda pode ser identificada como uma ciência aplicada, caracterizada pelo simples desenvolvimento de procedimentos e estratégias para obtenção e solução de problemas previamente determinados. (CACHAPUZ, et. al., 2005; SANTOS, et al., 2005).

Dentro deste contexto, de modo sintético e histórico, verifica-se na literatura especializada, que no Brasil, o ensino de Ciências na sua totalidade e em principal na EJA, passa a compor a partir dos anos de 1960 e 1970, sobretudo na sua base teórica e metodológica, um caráter predominantemente empirista-positivista, portanto, carente de questões socais e culturais (BRASIL, 1998 e CACHAPUZ, 2005)

Segundo Cachapuz, et al. (2005) e Gil Pérez (1991), na interface histórica dos anos de 1960 e 1970, o ensino de Ciências Naturais apresentou deficiência de cunho reflexivo em função do adestramento mecânico com o qual os professores foram treinados e reproduziam em suas aulas no ensino em geral, particularmente na EJA, pois, conforme elucidam Haddad e Di Pierro (2000), a história da educação de jovens e adultos neste cenário, estava a serviço do Movimento Brasileiro de Alfabetização (MOBRAL), cuja proposta, mantinham as práticas e ideologias da política autoritária em vigência. 
A vista disso, a partir dos anos de 1980 e 1990, afirmam Marandino, Salles, Ferreira (2009) e Kindel (2012), a ação docente em Ciências até então reduzida ao método científico e experimental, é de sobremaneira contestada face a ânsia de um ensino de natureza mais sóciohistórica, vinculado as necessidades, interesses e centralidade do aluno enquanto sujeito cultural e de ações crítico-reflexivas. Ainda nesse mesmo período, afirma Brasil (1998) o ensino das Ciências Naturais fica mais próximo das Ciências Humanas e Sociais, saindo de uma restrição natural, para um constructo mais humano.

O entendimento do professor como profissional reflexivo e crítico foi cunhado impreterivelmente por Schõn (1983) e Stenhouse (1975), e refere-se a ideia da prática docente desvinculada de pressupostos técnicos, uma vez que, o ensino requer juízo de valor e é caracterizado por situações instáveis, incertas, flexíveis, singulares, sensíveis à pesquisa, bem como, contraditórias. (CONTRERAS, 2002).

Pimenta e Ghedin (2012) ainda, complementam que, só o caráter reflexivo é importante, porém não é suficiente pois, para uma efetiva abordagem histórico-crítica, faz-se necessário uma segunda superação, de uma visão docente reflexiva para a adoção de um professor enquanto intelectual crítico, principalmente na EJA, que segundo Brasil (1996), carece de uma proposta didático-pedagógica articulada ao contexto de vida de seus alunos, sua atividade de trabalho e sua significação histórico-cultural.

Por todos esses apontamentos, Cachapuz, et al., (2005) e Freire (1996) advogam a necessidade de um ensino de Ciências de base teórico-epistemológica e metodológica centrada nas condições de apropriação do conhecimento pela figura discente, capaz de realizar uma formação do aluno crítica, ética e significativa.

Sendo assim, o presente artigo intenta compreender a partir de uma discussão históricocrítica quais das proposições teórico-metodológicas (técnica ou crítico-reflexiva) se revelam na atividade docente de professores de Ciências Naturais na Educação de Jovens e Adultos (EJA) no Brasil e suas articulações com o processo de aprendizagem dos alunos desta modalidade.

\section{METODOLOGIA}

Como mecanismo de execução dos objetivos delineados, o presente artigo se valeu de uma revisão de literatura problematizada sobre a ação docente em Ciências Naturais na EJA sob um paradigma histórico-crítico. Para isso, optou-se intencionalmente pela busca de Teses e Dissertações em três bases de dados: Scielo, BDTD, e periódicos da Capes, cujos descritores específicos foram: ensino de Ciências, EJA, pedagogia histórico-crítica, professor-reflexivo e profissional técnico. Também foram usadas em complemento, bibliografias de vários autores específicos sobre as temáticas de pesquisa, em principal: das Ciências Naturais como Chacapuz et, al. (2005); da EJA como Haddad e Di Pierro (2012); da Pedagogia Histórico-Crítica como Saviani (1997); além de Contreras (2002); Pimenta e Guedin (2012) para discussão do professor como técnico; reflexivo e intelectual crítico. Tais escolhas se deram para averiguar se a prática docente em ciências neste segmento de ensino se alicerça em situações teóricas e metodológicas exclusivamente técnicas e tradicionais ou possui caráter inovador para uma aprendizagem críticoreflexiva e emancipatória aos alunos desta modalidade de ensino.

\section{RESULTADOS}

Com base na literatura especializada sobre a temática, e nas publicações acadêmicas encontradas, percebe-se que os pressupostos teórico-metodológicos que têm orientado o ensino de Ciências sobretudo na EJA, mostram-se um tanto a-históricos, acríticos, descontextualizados e marcadamente instrumentais, portanto, tecnicistas. Nesse âmbito, estudos de Cachapuz, et al. (2005); Contreras (1998); Leite e Di Giorgi (2004); Pereira (2004) e Santos, et al. (2005) reforçam que, ainda é bastante atuante a concepção de ciência expressa pela hierarquia entre 
conhecimento teórico e técnico; aplicação de procedimentos cujos resultados já são predeterminados e fixos; visão produtivista da profissionalidade docente e ideia do professor enquanto cientista experimental.

Os achados acadêmicos também mostram-se incipientes sobre a ação docente em Ciências Naturais na EJA dentro de um viés histórico-crítico, uma vez que, ao se buscar nas bases de dados escolhidas e com os descritores determinados, foi encontrada apenas uma Dissertação nos últimos cinco anos que discute sobre a temática, a qual foi intitulada "O conhecimento em biologia na educação de jovens e adultos: aproximações com a pedagogia histórico-crítica" Desta maneira, os resultados deste trabalho revelam que o ensino de Ciências ainda conserva uma visão pragmática, o que faz necessário olhares mais atentos e contundentes sobre um apoio históricocrítico no ensino desta disciplina como recurso humanizante e de transformação social (CANCELLARA, 2017).

Ainda, é possível denotar segundo os achados mais significativos do ensino de Ciências na EJA, uma profícua necessidade para melhores adequações dos professores às concepções teóricas e metodológicas de ensino mais inovadoras, humanas e crítico-reflexiva, pois segundo Contreras (2002), a educação em geral e ensino de jovens e adultos em particular, têm presenciado uma tênue presença da racionalidade técnica nas suas configurações, o que advoga e carece de uma maior relevância social do ensino, sobretudo para um público com características históricoculturais.

Por fim, encontrou-se nas construções de Cancellara (2017); Contreras (2002); Leite e Di Giorgi (2004); Pimenta e Guedin (2012) e Tardif (2014), uma inegável e necessária recuperação da formação e ação reflexiva docente e do professor como intelectual crítico, para que haja uma mudança no cenário do ensino, então marcado por um repertório tecnicista, bem como, para que se extrapole as discussões da sala de aula e da escola para contextos e percepções multidimensionais e de mudanças histórico-culturais e sociais.

\section{DISCUSSÃO}

Em termos históricos, têm se certificado que o ensino de Ciências na EJA vem sendo conduzido mediante uma atitude profissional exclusivamente técnica, e isso exige olhares para um preparo na formação e atuação do professor dentro de uma ótica mais democrática e críticoreflexiva. Em outras palavras, verifica-se a importância de pesquisas e atitudes efetivas que coloquem em evidência a adoção de teorias e metodologias que permitam uma reflexão da práxis, posto que, ensinar segundo Contreras (2002), se caracteriza por situações incertas, instáveis e singulares, nas quais há conflitos de valor e não apenas situações instrumentais e mecânicas.

Assim, dentro de um paradigma histórico-crítico, um referencial teórico-metodológico deve se incumbir de estruturar e caracterizar uma compreensão de ciência e refletir suas implicações éticas, socioculturais, axiológicas e antropológicas, principalmente na EJA, caracterizada por uma multiplicidade cultural, etária, histórica e social (BRASIL, 2000; BRASIL, 2000; CACHAPUZ et al., 2005; CANCELLARA, 2017; GIL-PÉREZ et al., 2001; HADDAD e DI PIERRO, 2000). Sobre o aspecto etário ainda, Haddad e Di Pierro (2000), esclarecem o fato de que na atualidade, infelizmente assistimos uma ampla introdução de um público essencialmente juvenil na EJA, decorrente da defasagem idade/série e da massiva exclusão do ensino regular.

Portanto, Cachapuz et al., (2005); Contreras (2002); Gil-Pérez et al., (2001); Haddad e Di Pierro (2000) e Schõn (1983), consideram que uma teoria e metodologia significativa para o ensino de Ciências na EJA requer obrigatoriamente uma ruptura da racionalidade técnica e conquista da prática reflexiva, ou seja, situações sem burocracia que demandem necessária atitude ativa, mecanismos de interpretação, contextos transacionais e um diálogo reflexivo.

Sendo assim, verifica-se que o ensino de Ciências, em especial na EJA, no que corresponde aos aspectos teórico-metodológicos adotados precisa se atentar mais ao processo do que um 
produto final direto, sobretudo para alunos que não tiveram oportunidades de estudos na idade própria, bem como, por serem vítimas de mazelas sócio-históricas e político-culturais. (CANCELLARA, 2017)

\section{CONCLUSÃO}

Assim, entende-se, com base na questão de pesquisa elencada, quais as bases teóricometodológicas assumidas por docentes de Ciências Naturais na EJA, que ainda se caracterizam por uma condição de pura racionalidade técnica, ou seja, métodos lineares, passivos, instrumentais e produtivistas, além de pressupostos teóricos e epistemológicos de sobremaneira empírico-positivista, portanto, do professor como profissional técnico, calcado em conteúdos cognitivos e informativos. Deste modo, faz-se necessário a superação deste cenário para um ensino mais sócio-histórico, de cunho reflexivo e respaldo crítico, bem como, uma docência que assegure uma maior racionalidade prática para a formação de alunos mais autônomos e pensantes.

\section{REFERÊNCIAS}

AUGUSTINHO, E. O ensino de ciências na educação de jovens e adultos: uma avaliação nas escolas da baixada fluminense. 2010. 129p. Dissertação (Mestrado) - Programa de Pós-Graduação Stricto Sensu em Ensino de Ciências Nilópolis do Instituto Federal de Educação, Ciência e Tecnologia do Rio de Janeiro, Nilópolis, RJ.

BRASIL. Ministério de Educação e Cultura. LDB - Lei no 9394/96, de 20 de dezembro de 1996. Estabelece as diretrizes e bases da Educação Nacional. Brasília: MEC, 1996.

BRASIL. Secretaria da Educação e Cultura. Parâmetros Curriculares Nacionais: ciências naturais: terceiro e quarto ciclos. Brasília: MEC/SEF, 1998b. 136 p.

BRASIL. Diretrizes Curriculares Nacionais para a Educação de Jovens e Adultos. Parecer 11/2000. Brasília. 2000.

CACHAPUZ, A. et al. A Necessária renovação do ensino das ciências. São Paulo: Cortez, 2005. 263 p.

CANCELLARA, C. O Conhecimento em Biologia na Educação de Jovens e Adultos: Aproximações com a Pedagogia Histórico-Crítica. 2017. 177p. Dissertação (Mestrado) - Programa de PósGraduação em Educação para Ciência da Universidade Estadual Paulista "Julho de Mesquita Filho, Campus Bauru, SP. Disponível em: https://repositorio.unesp.br/bitstream/handle/11449/150472/cancellara_chp_me_bauru.pdf?seq uence=5\&isAllowed=y. Acesso em: 06 de Setembro de 2018.

CONTRERAS, J. Autonomia de professores. Tradução de Sandra Trabucco Valenzuela. São Paulo: Cortez, 2002. Cap. 4 e 5, 296 p.

FREIRE, P. Pedagogia da autonomia: saberes necessários à prática educativa. São Paulo: Paz e Terra, 1996.

GIL PÉREZ, D. jQué hemos de saber y saber hacer los profesores de ciencias? Intento de síntesis de las aportaciones de la investigación didáctica. Enseñanza de Las Ciencias. València, v.9 (I), p. 69-77. 1991. 
file://C:/Users/Luanaa/Documents/lucas/PEREZ\%20ARTIGO\%20CITA\%C3\%87\%C3\%830.pdf. Acesso em: 19 de Julho de 2018.

GIL-PÉREZ, D.; FERNÁNDEZ, I.; CARRASCOSA, J.; CACHAPUZ, A.; PRAIA, J. Por uma imagem não deformada do trabalho científico. Ciência \& Educação, 7 (2), p. 125-153. 2001. Disponível em: http://www.scielo.br/pdf/ciedu/v7n2/01.pdf. Acesso em: 19 de Julho de 2018.

HADDAD, S.; DI PIERRO, M. Escolarização de jovens e adultos. Revista Brasileira de Educação. Mai/Jun/Jul/Ago, no 4, 2000.

KINDEL, E. A docência em Ciências Naturais: construindo um currículo para o aluno e para a vida. Erechim: Edelbra, 2012. 128 p.

LEITE, Y.; DI GIORGI, C. Saberes docentes de um novo tipo na formação profissional do professor: alguns apontamentos. educacação v.29, n.2, p.135-145, Santa Maria, 2004. Disponível em: http://www.ufsm.br/ce/revista. Acesso em 18 de Junho de 2018.

MARANDINO. M.; SELLES. S.; FERREIRA. Marcia S. Ensino de Biologia: histórias e práticas em diferentes espações educativos. São Paulo: Cortez, 2009.

PEREIRA. J. Tendências históricas da educação dos jovens e adultos no Brasil: da subordinação a tentativas de emancipação. Educativa, Goiânia, v. 17, n. 1, p. 175-200, jan./jun. 2014.

PIMENTA, S.; GHEDIN, E. Professor reflexivo no Brasil: gênese e crítica de um conceito. São Paulo: Cortez, 2002.

SAVIANI. D. Pedagogia histórico-crítica: primeiras aproximações. São Paulo: Autores Associados, 1997.

SCHÕN, D. The reflective practitioner. Nova York: Basic Books, 1983.

SCHÖN. D. A. Formar professores como profissionais reflexivos. In: NÓVOA, A. (Org.). Os professores e sua formação. Lisboa: Dom Quixote, 1992.

STENHOUSE, L. An introduction to curriculum research and development. Londres: Heinemann, 1975.

TARDIF, M. Saberes docentes e formação profissional. 16. ed. - Petrópolis, RJ : Vozes, 2014. 